\title{
Reaksi Pasar Atas Pengungkapan Management Discussion and Analysis
}

\author{
Putu Aldhi Surata ${ }^{1}$ \\ Ida Bagus Putra Astika \\ ${ }^{1,2}$ Fakultas Ekonomi dan Bisnis Universitas Udayana (Unud), Bali, Indonesia \\ e-mail : putualdhis@gmail.com
}

\begin{abstract}
ABSTRAK
OJK menerbitkan POJK No.29/POJK.04/2016 yang mewajibkan pengungkapan MD\&A dalam laporan tahunan. Tujuan dari penelitian ini adalah untuk membuktikan secara empiris bahwa terdapat (1)reaksi pasar pada pengungkapan laporan tahunan,(2) pengaruh tingkat pengungkapan MD\&A terhadap abnormal return. Populasi penelitian menggunakan indeks KOMPAS100 berjumlah 100 emiten dengan total sampel yaitu 63 sample. Hasil uji statistik Wilcoxon menyatakan terdapat perbedaan sebelum dan sesudah pengungkapan annual report. Selanjutnya dilakukan uji regresi linier sederhana yang memberikan hasil bahwa pengungkapan MD\&A berpengaruh positif terhadap reaksi pasar yang diproksikan menggunakan abnormal return. Hasil uji menghasilkan pengungkapan MD\&A berpengaruh positif pada reaksi pasar melalui abnormal return sehingga diketahui pasar menggunakan informasi yang terkandung dalam MD\&A.
\end{abstract}

Kata kunci : Management discussion and analysis, abnormal return, annual report.

\begin{abstract}
OJK issues POJK No.29 / POJK.04 / 2016 which requires MD \& A disclosure in the annual report. The purpose of this study is to prove empirically that there are (1) market reactions in annual report disclosures, (2) the effect of $M D \& A$ disclosure level on abnormal returns. The study population used the KOMPAS100 index of 100 issuers with a total sample of 63 samples. The Wilcoxon statistical test results state that there are differences before and after the disclosure of the annual report. Furthermore, a simple linear regression test was conducted which gave the results that the $M D \& A$ disclosure had a positive effect on the market reaction that was proxied using abnormal return. The test results produce $M D \& A$ disclosures that have a positive effect on market reactions through abnormal returns so that the market is known to use the information contained in $M D \& A$.
\end{abstract}

Keywords : Management discussion and analysis, abnormal return, annual report.

\section{PENDAHULUAN}

Investor menggunakan informasi dalam laporan keuangan perusahaan untuk mengevaluasi dan memberi peringkat pada suatu perusahaan guna menentukan keputusan investasi. Menurut US SEC (1989), informasi berupa angka dalam laporan keuangan dan catatan singkat mengenai keuangan saja tidak cukup bagi 
investor untuk memutuskan kualitas laba dan kemungkinan kinerja masa lalu dijadikan indikator untuk prediksi dimasa depan. Karena itu diperlukan jenis informasi lainnya guna menjadi pertimbangan untuk menilai masa depan suatu perusahaan. Pada laporan keuangan tahunan perusahaan biasanya terdapat sesi Management Discussion and Analysis (MD\&A).

Pihak manajemen perusahaan dapat menggunakan bagian naratif dari laporan keuangan untuk mengkomunikasikan informasi yang jujur dan terpercaya (Kristi et al., 2002). MD\&A adalah penjelasan narasi dari laporan keuangan guna memudahkan pengguna laporan keuangan untuk memahami isi laporan. MD\&A mampu memberikan sudut pandang tambahan mengenai perusahaan yaitu sudut pandang dari pihak manajemen perusahaan. Manajemen dalam hal posisi lebih bagus atau baik untuk menyediakan informasi mengenai perusahaan daripada pihak lainnya. Laporan MD\&A bisa menjadi alat yang cukup mumpuni bagi manajemen dalam mengkomunikasikan bagaimana perusahaan membentuk nilai dan bagaimana agar proses membentuk nilai terus berlanjut.. MD\&A dalam kombinasi dengan laporan keuangan yang mana menyediakan peluang perusahaan untuk mengkomunikasikan efektivitas dalam mengelola sumber daya yang dimiliki dan langkah kedepannya untuk mencapai tujuan strategik perusahaan yang sudah ditetapkan sebelumnya. Salah satu prinsip dari MD\&A menurut Chartered Professional Accountant Canada adalah "MD\&A complements and supplements your financial statements, but does not form part of your financial statements". Maksud dari komplemen dari laporan keuangan disini adalah MD\&A menyajikan informasi kontekstual dan prospek yang tidak disajikan dalam 
financial statement sementara maksud dari suplemen sendiri yaitu MD\&A melengkapi laporan keuangan dengan memberikan analisa dari informasi yang terdapat di MD\&A.

Lebih jelas lagi, dalam supplementing financial statement pengungkapan MD\&A harus (1) menjelaskan kondisi dan peristiwa yang membentuk hasil yang tercermin dalam laporan keuangan dan (2) membantu dalam memahami kondisi dan peristiwa sebelumnya yang bisa memengaruhi prospek perusahaan kedepannya. Sementara untuk complementing financial statement, MD\&A harus menyediakan informasi kualitatif dan kuantitatif mengenai bisnis yang dijalani dan performanya yang tidak dilaporkan dalam laporan keuangan akan tetapi relevan dengan evaluasi terhadap kinerja masa lalu dan menilai prospek kedepannya.

Laporan MD\&A yang lengkap dan terbuka bisa menjadi informasi dengan bias yang relatif rendah sehingga bisa mampu mengetahui risiko saham yang terlibat serta dapat meningkatkan ketepatan dalam mengambil keputusan investasi. Akan tetapi relevansi dari laporan tahunan masih diragukan oleh Francis \& Schipper (2013) menemukan mengenai relevansi dari laporan keuangan dalam penelitiannya yang menunjukkan bahwa relevansi laporan keuangan mengalami penurunan dengan pembanding perusahaan yang bergerak di bidang teknologi dengan perusahaan yang bergerak di bidang non teknologi. Koonce et al. (2016) dalam penelitiannya mengetahui bahwa investor disesatkan oleh penjelasan parsial dari manajemen pada bagian MD\&A ketika manajemen menjelaskan evaluasi mengenai perusahaan sehingga prediksi pendapatan yang dibuat oleh 
investor menjadi lebih tinggi. Oleh karena terjadinya penurunan relevansi dan maka pemerintah dalam hal ini Otoritas Jasa Keuangan mengadakan Annual Report Award. Penilaian MD\&A menggunakan kriteria yang digunakan dalam penilaian Annual Report Award. Annual Report Award (ARA) merupakan kompetisi tahunan yang diselenggarakan oleh Otoritas Jasa Keuangan (OJK), bekerja sama dengan Kementerian BUMN, Direktorat Jenderal Pajak, Bank Indonesia, Bursa Efek Indonesia, Komite Nasional Kebijakan Governance (KNKG), dan Ikatan Akuntan Indonesia. Tujuan dari diadakannya ARA adalah untuk meningkatkan kualitas informasi dan governance melalui Annual Report atau buku laporan tahunan sebuah perusahaan. Sejak diselenggarakannya ARA pada 2002 hingga kini, terjadi sebuah peningkatan kualitas informasi pada laporan keuangan setiap tahunnya. Dalam penelitian yang dilakukan (Mayew, Sethuraman and Venkatachalam, 2015) menyatakan bahwa MD\&A mampu memberikan informasi mengenai keberlangsungan usaha dari perusahaan dan mampu memprediksi kebangkrutan suatu perusahaan tiga tahun lebih awal. Contoh yang mendukung pernyataan dari Mayew yaitu pailitnya PT Cipaganti Citra Graha Tbk dimana terhitung mulai tahun 2014 sudah mengindikasikan kebangkrutan dalam seksi MD\&A pada laporan keuangan perusahaan dan pada tahun 2016 PT Cipaganti Citra Graha dinyatakan pailit. Meskipun MD\&A menyediakan informasi yang berguna tetapi perlu diingat bahwa MD\&A tidak menyajikan semua informasi material perusahaan karena jenis informasi apa saja yang wajib terkandung dalam MD\&A sudah diatur dalam KEP-431/BL/2012. Berdasarkan penelitian sebelumnya, MD\&A hanya digunakan dalam pengambilan keputusan 
investasi bagi kalangan investor kaya tetapi tidak berpengalaman (Epstein and Pava, 1995). Sedikitnya pengguna yang memanfaatkan annual report khususnya MD\&A juga didukung oleh Apriyanti \& Sidanti (2018), Sriwidodo \& Sumaryanto (2017) yang menemukan bahwa pasar tidak merespon annual report award yang dilihat dengan tidak adanya perbedaan abnormal return dan trading volume activity sebelum dan sesudah tanggal pengumuman. Hal ini sungguh disayangkan bagi para pengambil keputusan mengingat kandungan informasi dalam MD\&A yang lengkap dan terbuka akan berguna untuk memprediksi performa perusahaan kedepan seiring dengan meningkatnya jumlah pengungkapan sukarela dalam annual report (Sriwidodo and Sumaryanto, 2017) . Konten dalam MD\&A adalah pengulangan dari informasi dalam laporan tahunan perusahaan yang dirasa penting oleh manajemen sehingga informasi tersebut cukup informatif bagi investor ( $\mathrm{Li}, 2017)$, dan semakin kompleks isi dari MD\&A suatu laporan tahunan perusahaan maka semakin besar kemungkinan perusahaan tersebut mengalahkan laba pada peride sebelumnya (Lo et al., 2017). Karena sebab yang telah dipaparkan sebelumnya maka peneliti ingin mengetahui reaksi pasar melalui tindakan para investor dalam merespon informasi public tentang pengungkapan dalam MD\&A yang dapat diukur dengan abnormal return dan trading volume activity. Tujuan dari penelitin ini yaitu (1)untuk membuktikan secara empiris bahwa terdapat reaksi pasar terhadap pengumuman annual report, (2)untuk membuktikan secara empiris variabel Management \& Discussion Analysis berpengaruh pada abnormal return, (3) untuk membuktikan secara empiris 
variabel Management Discussion \& Analysis berpengaruh pada trading volume activity.

Konten dari laporan tahunan emiten terdapat berbagai informasi mengenai emiten yang bersangkutan sehingga memungkinkan investor untuk menggunakan informasi, pernyataan ini didukung oleh Paramita \& Rizal (2015) dalam penelitiannya menemukan bahwa publikasi informasi keuangan pada website perusahaan direspon oleh pasar yang tercermin dari adanya abnormal return saham dan tingkat pengungkapan informasi keuangan pada website perusahaan juga berpengaruh terhadap respon pasar. Selain itu pengumuman terhadap annual report award direspon oleh pasar dengan melihat terdapat perbedaan return sebelum dan sesudah pengumuman (Ekawati, 2011). Didalam annual report terdapat MD\&A. Pengungkapan dalam MD\&A cenderung berisi pengulangan dari isi laporan tahunan, akan tetapi pengulangan tersebut memberikan informasi spesifik mengenai perusahaan yang cukup informatif bagi investor ( $\mathrm{Li}, 2017)$, karena informative maka diharapkan direaksi oleh pasar. Konten dalam MD\&A ada yang wajib untuk diungkapkan dan ada yang sukarela untuk diungkapkan, dalam penelitian Gunawan \& Lina (2015) menemukan bahwa pengungkapan wajib dan sukarela dalam laporan tahunan direaksi oleh pasar Widiastuti (2004) menyatakan bahwa luas ungkapan sukarela dalam laporan tahunan berpengaruh positif terhadap Earning Response Coefficient yang berarti bahwa pengungkapan sukarela digunakan oleh pelaku pasar saham. Berdasarkan hasil penelitian terdahulu maka dapat ditarik hipotesis :

$\mathrm{H}_{1}$ : Terdapat reaksi pasar terhadap pengumuman annual report. 
Pengungkapan manajemen dalam MD\&A dapat membantu investor untuk mengklarifikasi dan merupakan nilai tambah bagi laporan keuangan. MD\&A dan pengungkapan naratif lainnya dapat memberikan informasi tambahan yang berguna dalam menjelaskan kemungkinan kebangkrutan yang akan dialami oleh perusahaan dimasa yang akan datang (Tennyson et al., 1990). Sementara menurut Sun (2010) dalam penelitiannya yang berjudul "Do MD\&A Disclosures Help Users Interpret Disproportionate Inventory Increases ?" menyatakan bahwa pengungkapan naratif dalam MD\&A mengenai persediaan mampu mengungkapkan peningkatan jumlah persediaan yang tidak wajar sehingga berguna dalam memprediksi kinerja dimasa yang akan datang. (Mayew, 2012) juga menyatakan hal yang sama dengan (Sun, 2010) dan (Tennyson, Ingram and Dugan, 1990) bahwa MD\&A berguna dalam memprediksi kebangkrutan lebih awal tiga tahun daripada memprediksi menggunakan rasio keuangan. Mayew et al. (2015) menemukan hasil bahwa pengungkapan MD\&A memiliki informasi penjelas tambahan untuk memprediksi kebangkrutan apabila digunakan dalam jangka waktu lebih dari satu tahun. Lindrianasari et al. (2017) menemukan hasil bahwa laporan MD\&A berpengaruh positif dan signifikan pada return dan TVA. Pengungkapan MD\&A berkaitan positif dan signifikan terhadap perubahan penjualan, earning per share, dan capital expenditures dalam satu periode kedepan (Bryan and Bryan, 2014). Perusahaan dengan tingkat kepercayaan (diproksikan dengan jumlah kata unik pada MD\&A) lebih tinggi maka volatilitas return saham juga lebih tinggi (Audi et al., 2015).Pengumuman laba direaksi oleh pasar di negara yang memiliki tingkat kepercayaan tinggi, ketika regulasi lemah 
maka investor akan mengandalkan kepercayaan dalam mengambil keputusan ekonomi (Pevzner et al., 2015). Annual report direaksi oleh pasar ditandai dengan reaksi atas harga yang signifikan pada pengumuman laba tahunan baik itu untuk perusahaan yang menyampaikan berita baik atau buruk (Haw, Qi and Wu, 2000). Dari hasil penelitian sebelumnya maka dapat ditarik hipotesis yakni :

$\mathrm{H}_{2}$ : Pengungkapan MD\&A berpengaruh positif pada Abnormal Return.

\section{METODE PENELITIAN}

Jenis penelitian yang digunakan adalah studi peristiwa (event study). Studi peristiwa (event study) merupakan studi yang mempelajari reaksi pasar terhadap suatu peristiwa yang diinformasinya dipublikasikan sebagai suatu pengumuman (Hartono, 2017:643). Peristiwa yang diuji adalah pada saat adanya pengumuman laporan keuangan tahunan perusahaan dengan menggunakan jendela peristiwa selama 14 hari. Penggunaan jendela peristiwa selama 14 hari bertujuan menghindari bias atas peristiwa (misalnya corporate action) yang mungkin terjadi selama periode pengamatan dan mengantisipasi lambatnya respon pasar karena informasi naratif cenderung memakan waktu lebih lama untuk diolah pengguna informasi. Informasi dari pengungkapan MD\&A dalam laporan keuangan tahunan akan diuji terhadap reaksi investor dalam pasar modal yang diproksikan dengan abnormal return. Populasi dari penelitian ini adalah semua perusahaan yang terdaftar indeks KOMPAS 100 periode Februari - Juli 2017. Jumlah dari populasi adalah 100 perusahaan. Sampel adalah bagian dari jumlah dan karakteristik yang dimiliki oleh populasi tersebut (Sugiyono, 2017). Sample dalam penelitian ini 
adalah seluruh perusahaan yang terdaftar dalam indeks KOMPAS 100 periode Februari - Juli 2017 yang memenuhi kriteria .

Metode penentuan sampel yakni menggunakan metode purposive sampling dengan kriteria yaitu : (1)Menerbitkan laporan keuangan tahunan tahun 2017, (2) Melaporkan Management Discussion \& Analysis, (3) Tidak terdapat peristiwa lain atau corporate action selain informasi penerbitan laporan keuangan tahunan selama rentang waktu yang diamati

Lingkup penelitian ini dibatasi pada reaksi pasar yang diproksikan dengan abnormal return saham dan TVA terhadap pengungkapan manajemen dalam MD\&A. Variabel bebas dalam penelitian ini yaitu MD\&A (X) sementara variabel terikat Abnormal Return Saham (Y1) dan Trading Volume Activity (Y2).

Pada Tabel 1 menunjukkan tiap elemen dari MD\&A. Penelitian ini akan menyelidiki informasi dalam laporan keuangan tahunan suatu perusahaan dengan menggunakan kriteria dalam indeks pengungkapan MD\&A yang digunakan dalam penilaian Annnual Report Award tahun 2016. Indeks ini memiliki 17 kriteria dengan 15 subkriteria dalam tiap kriteria utamanya. Untuk setiap elemen dalam MD\&A yang diungkapkan akan diberikan skor 1 sementara yang tidak mengungkapkan diberikan skor 0 . Sehingga skor elemen tersebut dapat dijumlahkan dan diubah menjadi bentuk rasio. Total elemen dari MD\&A yang lengkap menurut ARA ada 66, jadi skor maksimal penghitungan elemen MD\&A adalah 66. Penelitian ini menggunakan perhitungan abnormal return yaitu marketadjusted model. Market-adjusted model (model sesuaian-pasar) mengganggap 
bahwa penduga yang terbaik untuk mengestimasi return suatu sekuritas adalah return indeks pasar pada saat tersebut ( Hartono, 2017: 679).

Tabel 1.

Kriteria MD\&A ARA 2016

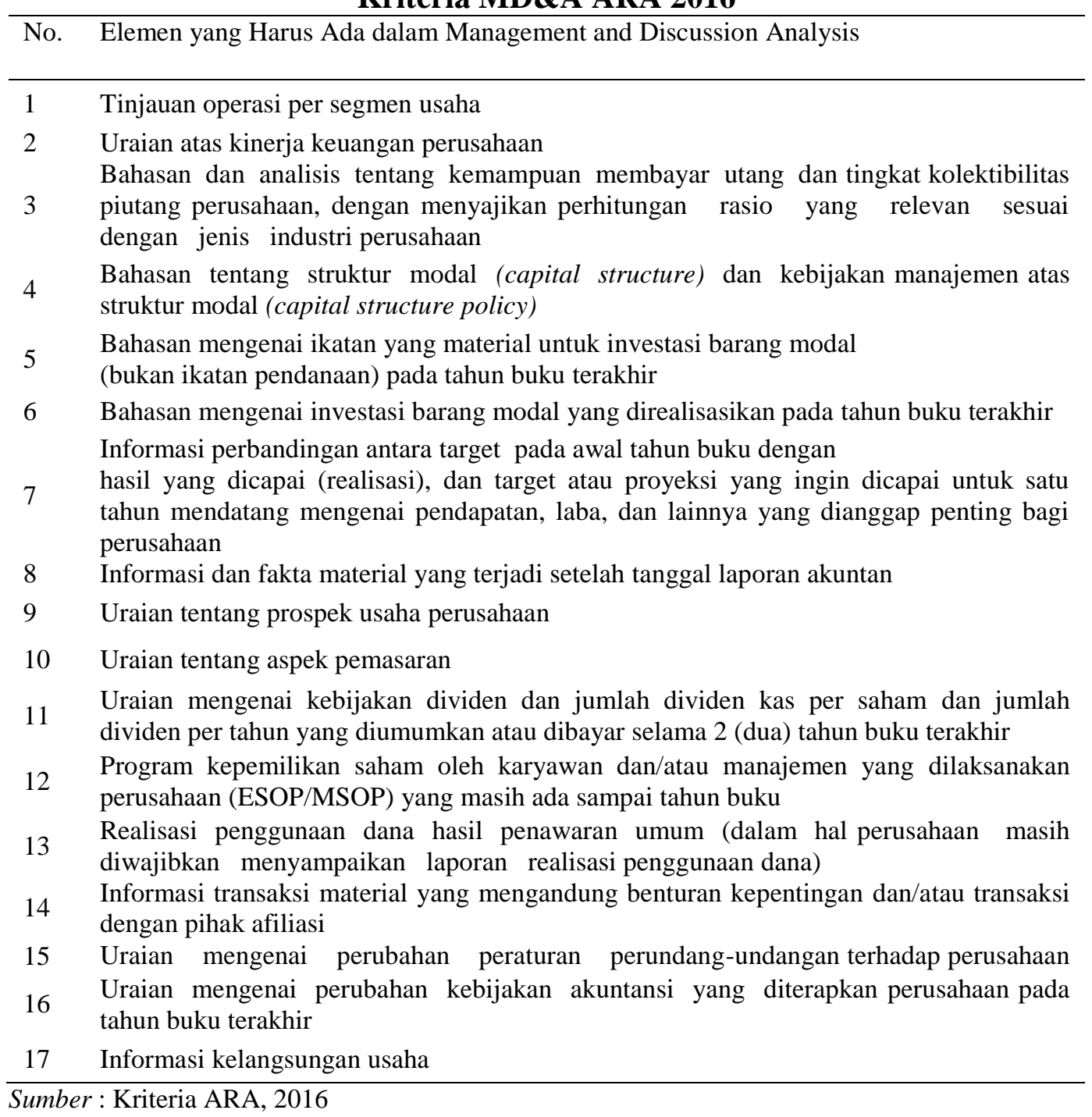

Karena pasar modal di Indonesia adalah pasar modal dalam tahap sedang berkembang, dimana pada tahap tersebut pasar modal mempunyai ciri yaitu sebagian besar saham yang diperdagangkan transaksinya tidak likuid sehingga saham tersebut jarang diperjual-belikan, akibatnya banyak saham yang menghasilkan return nol selama tidak terjadi transaksi (Kurniasari dan 
Nugraheni, 2003). Sedianingtiasi (2010), mengatakan bahwa dengan menggunakan market-adjusted model, maka tidak perlu menggunakan periode estimasi untuk membentuk model. Langkah-langkah untuk menghitung abnormal return, sebagai berikut:

Menghitung return realisasian/actual return $\left(\mathrm{R}_{\mathrm{i}, \mathrm{t}}\right)$. Return realisasian atau return sesungguhnya adalah return yang terjadi pada waktu ke-t merupakan selisih antara harga sekuritas hari sekarang relatif terhadap harga kemarin. Dapat dihitung dengan rumus sebagai berikut :

$$
\mathrm{R}_{\mathrm{i}, \mathrm{t}}=\left(\mathrm{P}_{\mathrm{i}, \mathrm{t}}-\mathrm{P}_{\mathrm{i}, \mathrm{t}-1)}\right) / \mathrm{P}_{\mathrm{i}, \mathrm{t}-1}
$$

Keterangan:

$\mathrm{R}_{\text {it }}$ : return individual saham i pada saat $\mathrm{t}$

$P_{t}$ : harga penutupan saham i pada saat $t$

$\mathrm{P}_{\mathrm{t}-1}$ : harga penutupan saham i pada saat $\mathrm{t}-1$

Menghitung return pasar harian/expected return $\left(\mathrm{R}_{\mathrm{m}, \mathrm{t}}\right)$. Return ekspetasian merupakan return yang diestimasi (Hartono, 2017:648). Estimasi return ekspetasian dalam penelitian ini menggunakan harga index IHSG pada hari sekarang relatif terhadap harga kemarin. Dapat dihitung dengan rumus sebagai berikut :

$$
R m, t=\frac{I H S G t-I H S G_{t-1}}{I H S G_{t-1}}
$$

Keterangan:

$\mathrm{Rm}_{\mathrm{t}} \quad$ : tingkat return pasar pada saat $\mathrm{t}$

$\mathrm{IHSG}_{\mathrm{t}}$ : Indeks Harga Saham Gabungan pada saat $\mathrm{t}$

IHSG $_{\mathrm{t}-1} \quad$ : Indeks Harga Saham Gabungan pada saat t- 1 
Putu Aldhi Surata dan Ida Bagus Putra Astika. Reaksi ...

Menghitung abnormal return. Abnormal return adalah selisih antara return sesungguhnya dengan return ekspetasian yang dirumuskan menggunakan market-adjusted abnormal return sebagai berikut:

$$
A R_{i, t}=R_{i, t}-R_{m, t}
$$

Sumber: Hartono (2017:648)

Keterangan:

$\mathrm{AR}_{\mathrm{t}} \quad$ : abnormal return saham i saat $\mathrm{t}$

$\mathrm{R}_{\mathrm{it}}$ : return individual saham i saat $\mathrm{t}$

$\mathrm{Rm}_{\mathrm{t}} \quad$ : tingkat return pasar saham saat $\mathrm{t}$

Menghitung Rata-Rata Return Tak Normal. Rata - rata return tak normal tiap sekuritas dihitung dengan membagi abnormal return dengan jumlah sekuritas yang terpengaruh dengan suatu peristiwa. Menurut Tandeilin (2010), rumusan untuk menghitung rata-rata abnormal return sebagai berikut :

$$
A A R_{t}=\frac{\sum_{i=1}^{K} A R_{i t}}{K}
$$

Keterangan :

AARt $=$ Rata-rata return tak normal

$A R_{i t}=$ Abnormal Return Sekuritas ke-i

$\mathrm{K}=$ Jumlah Sekuritas yang terpengaruh

Sebelum melakukan uji untuk membuktikan $\mathrm{H}_{2}$ dan $\mathrm{H}_{3}$ maka dilakukan uji Wilcoxon untuk menjawab $\mathrm{H}_{1}$

\section{HASIL DAN PEMBAHASAN}

Sebelum melanjutkan dengan uji statistik maka perlu dipilih terlebih dahulu sampel yang akan digunakan dalam penelitian. Penelitian ini menggunakan 
metode purposive sampling dengan hasil yang bisa dilihat pada Tabel 2 . Berdasarkan hasil seleksi pemilihan sampel pada Tabel 2. maka didapatkan total sampel sebanyak 63 emiten setelah dilakukan seleksi populasi sesuai dengan kriteria.

Tabel 2.

Hasil Seleksi Pemilihan Sampel

\begin{tabular}{clc}
\hline No & \multicolumn{1}{c}{ Kriteria } & Jumlah \\
\hline 1 & Menerbitkan laporan keuangan tahunan tahun 2017 & 100 \\
2 & Tidak melaporkan Management Discussion \& Analysis & $(1)$ \\
3 & $\begin{array}{l}\text { Tidak terdapat peristiwa lain atau corporate action selain } \\
\text { informasi penerbitan laporan keuangan tahunan selama } \\
\text { rentang waktu yang diamati }\end{array}$ & $(36)$ \\
Total sampel & 63 \\
\hline
\end{tabular}

Sumber : Data diolah, 2019

Berdasarkan tabel 3, variabel dependen perubahan abnormal return memiliki nilai rata-rata 4,24, standar deviasi sebesar 27,49 dengan nilai minimum -124,04 dimiliki oleh emiten berkode BBRI sementara nilai maksimum 163,05 dimiliki oleh emiten berkode KRAS.

Tabel 3. Statistik Deskriptif

\begin{tabular}{lccccc}
\hline & N & Minimum & Maximum & Mean & $\begin{array}{c}\text { Std. } \\
\text { Deviation }\end{array}$ \\
\hline $\begin{array}{l}\text { Perubahan Abnormal } \\
\text { Retrn }\end{array}$ & 63 & -124.0490 & 163.0561 & 4.245859 & 27.4981578 \\
MD\&A & 63 & .1406 & .8182 & .464218 & .1538810 \\
Valid N (listwise) & 63 & & & & \\
\hline $\begin{array}{l}\text { Sumber : Data diolah, 2019 } \\
\text { Mumber }\end{array}$ & & & & &
\end{tabular}

Berdasarkan tabel 3, variabel independen Management Discussion and Analysis memiliki nilai rata-rata 0,46 , standar deviasi sebesar 0,15 dengan nilai minimum 0,14 dimiliki oleh emiten berkode PWON sementara nilai maksimum 0,81 dimiliki oleh emiten berkode WTON. 
Sebelum melakukan uji regresi linier sederhana, dilakukan Uji Wilcoxon terlebih dahulu untuk membuktikan hipotesis pertama.

Tabel 4.

Hasil Uji Wilcoxon Rata-Rata Abnormal Return Sebelum dan Sesudah Pengumuman Annual Report

\begin{tabular}{lr} 
& AR_Sesudah - AR_Sebelum \\
\hline Z & $-2.908^{\mathrm{b}}$ \\
Asymp. Sig. (2-tailed) & .004 \\
\hline Sumber : Data diolah, 2018 &
\end{tabular}

Berdasarkan hasil pengolahan dengan menggunakan SPSS versi 22 dapat dilihat pada Tabel 4 menunjukkan rata-rata hasil pengujian Sig. (2-tailed) 0,004< 0,050. Berdasarkan perolehan tersebut maka dapat disimpulkan bahwa terdapat reaksi pasar yang diproksikan dengan abnormal return pada pengumuman Annual Report

Tabel 5.

Hasil Uji Wilcoxon Rata-Rata Trading Volume Activity Sebelum dan Sesudah Pengumuman Annual Report

Z

TVA_Sesudah - TVA_Sebelum

Asymp. Sig. (2-tailed)

$-2.303^{b}$

Sumber : Data diolah, 2019

Berdasarkan hasil pengolahan dengan menggunakan SPSS versi 22 dapat dilihat pada Tabel 5 menunjukkan rata-rata hasil pengujian Sig. (2-tailed) 0,021 < 0,05. Berdasarkan perolehan tersebut maka dapat disimpulkan bahwa terdapat reaksi pasar yang diproksikan menggunakan Trading Volume Activity pada pengumuman Annual Report. 
Hipotesis pertama dari penelitian ini adalah adanya reaksi pasar yang diproksikan dengan Abnormal Return dan TVA pada periode jendela. Berdasarkan hasil uji Wilcoxon didapatkan hasil bahwa terdapat perbedaan abnormal return dan TVA sebelum dan sesudah tanggal pengungkapan laporan tahunan. Karena terdapat perbedaan ini maka dapat diketahui bahwa terdapat reaksi dari pelaku pasar saham pada saat pengumuman laporan tahunan emiten.

Hasil penelitian ini bertolak belakang dengan hasil penelitian Rizki (2015) yang menyatakan bahwa pengungkapan sukarela pada laporan tahunan emiten tidak berpengaruh pada harga saham meskipun dalam penelitiannya menyatakan bahwa terdapat perbedaan rata rata abnormal return sebelum dan sesudah pengungkapan laporan tahunan. Hasil penelitian ini mendukung hasil penelitian dari Paramita \& Rizal (2015) dan Widiastuti (2004) bahwa pengungkapan informasi laporan tahunan dan pengungkapan sukarela direaksi oleh pasar.

Tahap selanjutnya adalah melakukan uji regresi linier berganda untuk membuktikan hipotesis kedua dan ketiga. Salah satu syarat untuk menggunakan alat analisis statistik parametrik adalah harus lolos uji asumsi klasik. Uji asumsi klasik yang pertama adalah uji normalitas residual. Uji normalitas ini bertujuan untuk mengetahui apakah residual dari model regresi yang dibuat berdistribusi normal atau tidak. Dalam penelitian ini uji normalitas dilakukan dengan menguji normalitas residual dengan menggunakan uji Run-test Normalitas. Jika probabilitas signifikansi nilai residual lebih besar dari 0,05 maka data tersebut dikatakan berdistribusi normal. 
Tabel 6.

Hasil Uji Normalitas

\begin{tabular}{lc}
\hline & $\begin{array}{c}\text { Unstandardized Residual } \\
\text { MD\&A }\end{array}$ \\
\hline Total Cases & 63 \\
Run-test Z & 0,129 \\
Asymp. Sig. (2-tailed) & 0,897 \\
\hline
\end{tabular}

Sumber: Data diolah, 2019

Berdasarkan hasil analisis Pengungkapan MD\&A terhadap Abnormal Return pada Tabel 6 didapat nilai signifikansi sebesar 0,897 dan hasil analisis Pengungkapan MD\&A terhadap Trading Volume Activity menunjukkan nilai signifikansi sebesar 0,373. Kedua nilai tersebut memiliki yang lebih besar dari 0,05 Oleh karena nilai signifikansi uji Run-test Normalitas lebih dari 0,05 maka dapat disimpulkan bahwa model persamaan regresi tersebut berdistribusi normal.

Uji asumsi klasik kedua yaitu uij heteroskedastisitas. Uji heteroskedastisitas ini bertujuan untuk mengetahui apakah dalam model regresi terjadi ketidaksamaan varians dari residual satu pengamatan ke pengamatan lain yang dilakukan dengan uji Glejser. Model regresi yang baik adalah yang tidak mengandung gejala heteroskedastisitas atau mempunyai varians yang homogen. Jika variabel bebas yang diteliti tidak mempunyai pengaruh signifikan atau nilai signifikansinya lebih dari 0,05 terhadap nilai absolute residual, berarti model regresi tidak mengandung gejala heteroskedastisitas. Hasil pengujian heteroskedastisitas disajikan pada Tabel 7 berikut.

Tabel 7.

Hasil Uji Heteroskedastisitas

\begin{tabular}{lc}
\hline \multicolumn{1}{c}{ Pengungkapan MD\&A terhadap Abnormal Return } \\
\hline Signifikansi & 0,147 \\
\hline Sumber: Data diolah, 2019
\end{tabular}


Pada Tabel 7 dapat dilihat bahwa nilai Signifikansi dari variabel Pengungkapan MD\&A terhadap Abnormal Return sebesar 0,147, dan nilai signifikansi Pengungkapan MD\&A terhadap Trading Volume Activity sebesar 0,759. Nilai tersebut lebih besar dari 0,05 yang berarti tidak terdapat pengaruh antara variabel bebas terhadap absolute residual. Dengan demikian, model yang dibuat tidak mengandung gejala heteroskedastisitas.

Berdasarkan uraian pada Tabel 6 dan Tabel 7 di atas, menunjukkan bahwa semua uji asumsi klasik sudah terpenuhi sehingga hasil analisis regresi layak untuk dibahas lebih lanjut. Setelah semua asumsi klasik terpenuhi, maka selanjutnya memaparkan hasil analisis regresi linier sederhana. Perhitungan koefisien regresi linier sederhana dilakukan dengan analisis regresi melalui software SPSS 22.0 for Windows, diperoleh hasil yang ditunjukan pada Tabel 8 .

Tabel 8.

Rekapitulasi Hasil Analisis Regresi Linier Sederhana

\begin{tabular}{lcccccc}
\hline & \multicolumn{2}{c}{$\begin{array}{l}\text { Unstandardized } \\
\text { Coefficients }\end{array}$} & $\begin{array}{c}\text { Standardized } \\
\text { Coefficients }\end{array}$ & & \\
\cline { 2 - 5 } & B & Std. Error & Beta & T & Sig. \\
\hline MD\&A $\rightarrow$ Abnormal Retun & .263 & .124 & .263 & & 2.125 & .038 \\
\hline Sumber $:$ Data diolah, 2019 & & & & & &
\end{tabular}

Nilai koefisien regresi Pengungkapan MD\&A terhadap Abnormal Return dan Trading Volume Activity memiliki nilai signifikansi uji t kurang dari 0,05 dengan arah koefisien regresi positif. Hal ini menunjukkan bahwa Pengungkapan MD\&A memiliki pengaruh yang positif dan signifikan terhadap variabel Abnormal Return dan Trading Volume Activity.

Berdasarkan tabel 8 diatas maka dapat dibentuk sebuah persamaan regresi dalam penelitian ini yaitu : 


\section{Abnormal Return $=-3.175 \mathrm{E}^{-7}+0.263 \mathrm{MD} \& \mathrm{~A}$}

Berdasarkan persamaan regresi yang terbentuk dapat disimpulkan beberapa hal yakni : (1)Nilai konstanta $-3.175 \mathrm{E}^{-7}$ dapat diartikan bahwa apabila variabel MD\&A konstan, maka abnormal return akan bernilai $-3.175 \mathrm{E}^{-7}$, (2)Nilai koefisien regresi dari variabel MD\&A sebesar 0.263 memiliki makna bahwa jika tingkat pengungkapan MD\&A tiap emiten meningkat, maka abnormal return tiap emiten akan meningkat sebesar 0.263

Koefisien determinasi $\left(\mathrm{R}^{2}\right)$ digunakan untuk mengetahui dan mengukur kemampuan model dalam menerangkan variasi variabel independen. Peneliti menggunakan nilai adjusted $\mathrm{R}^{2}$ pada saat mengevaluasi yang mana model regresi terbaik, karena tidak seperti $\mathrm{R}^{2}$, nilai adjusted $\mathrm{R}^{2}$ dapat naik atau turun apabila satu variabel independen ditambahkan ke dalam model.

Tabel 9.

Hasil Uji Koefisien Determinasi $\left(\mathbf{R}^{2}\right)$

\begin{tabular}{lc}
\hline & Pengungkapan MD\&A terhadap Abnormal Return \\
\hline R Square & 0,069 \\
Adjusted R Square & 0,054 \\
\hline Sumber : Data diolah, 2019 &
\end{tabular}

Hasil uji pada Tabel 9 memberikan hasil dimana diperoleh besarnya adjusted $\mathrm{R}^{2}$ pada Pengungkapan MD\&A terhadap Abnormal Return adalah sebesar 0,054. Ini berarti variasi Abnormal Return dapat dipengaruhi secara signifikan oleh variabel Pengungkapan MD\&A sebesar 5,4 persen, sedangkan sisanya sebesar 94,6 persen dijelaskan oleh faktor-faktor lain yang tidak dijelaskan dalam model penelitian.

Uji kelayakan model bertujuan untuk mengetahui apakah Pengungkapan MD\&A yang diidentifikasi tepat digunakan memprediksi Abnormal Return dan 
Trading Volume Activity. Uji ini sering juga disebut dengan uji $\mathrm{F}$ yang dapat dilihat pada Tabel 10 berikut :

Tabel 10.

\section{Hasil Uji Kelayakan Model (Uji F)}

\begin{tabular}{lcc}
\hline & $\begin{array}{c}\text { Pengungkapan MD\&A } \\
\text { terhadap Abnormal Return }\end{array}$ & $\begin{array}{c}\text { Pengungkapan MD\&A terhadap Trading } \\
\text { Volume Activity }\end{array}$ \\
\hline F & 4,516 & 12,466 \\
Signifikansi F & 0,038 & 0,001 \\
\hline Sumber : Data diolah, 2019 &
\end{tabular}

Hasil uji F (Ftest) pada Pengungkapan MD\&A terhadap Abnormal Return dalam Tabel 10 menunjukkan bahwa nilai signifikansi P value 0,038 yang kurang dari $\alpha=0,050$, ini berarti model yang digunakan pada penelitian ini adalah layak.. Hal ini berarti model dapat digunakan untuk analisa lebih lanjut atau dengan kata lain model dapat digunakan untuk memproyeksikan karena hasil goodness of fitnya baik dengan nilai signifikansi $\mathrm{P}$ value 0,038 .

Hasil uji F (Ftest) pada Pengungkapan MD\&A terhadap Trading Volume Activity dalam Tabel 8 menunjukkan bahwa nilai signifikansi P value 0,001 yang lebih kecil dari $\alpha=0,050$, ini berarti model yang digunakan pada penelitian ini adalah layak.. Hal ini berarti model dapat digunakan untuk analisa lebih lanjut atau dengan kata lain model dapat digunakan untuk memproyeksikan karena hasil goodness of fitnya baik dengan nilai signifikansi $\mathrm{P}$ value $0,001$.

Kriteria pengujian untuk menjelaskan interpretasi pengaruh antar masingmasing variabel yakni apabila nilai signifikansi $<0,05$ maka $\mathrm{H}_{0}$ ditolak dan $\mathrm{H}_{1}$ diterima. Sebaliknya, jika nilai signifikansi > 0,05 maka $\mathrm{H}_{0}$ diterima dan $\mathrm{H}_{1}$ ditolak. 
Berdasarkan hasil analisis pengaruh Pengungkapan MD\&A terhadap Abnormal Return diperoleh nilai signifikasi sebesar 0,038 dengan nilai koefisien regresi positif sebesar 0,263. Nilai Signifikansi $0,038<0,050$ mengindikasikan bahwa $\mathrm{H}_{0}$ ditolak dan $\mathrm{H}_{1}$ diterima. Hasil ini mempunyai arti bahwa Pengungkapan MD\&A berpengaruh positif dan signifikan terhadap Abnormal Return. Hipotesis kedua dari penelitian ini menyatakan bahwa pengungkapan MD\&A berpengaruh terhadap perubahan Abnormal Return. Berdasarkan hasil uji hipotesis didapatkan hasil bahwa pengungkapan MD\&A berpengaruh positif dan signifikan terhadap perubahan abnormal return yang berarti jika semakin tinggi tingkat pengungkapan MD\&A maka semakin tinggi tingkat perubahan abnormal return, begitu pula sebaliknya. Hasil penelitian ini mendukung penelitian sebelumnya yang dilakukan oleh Lindrianasari et al. (2017), dan Tennyson, Ingram and Dugan (1990). Mayew et al. (2015) menyatakan bahwa pengungkapan MD\&A memiliki informasi penjelas tambahan untuk memprediksi kebangkrutan apabila digunakan dalam jangka waktu lebih dari satu tahun yang dapat digunakan oleh investor dalam pertimbangan investasi sehingga pengungkapan MD\&A memiliki pengaruh ke pelaku pasar saham dalam hal ini adalah investor dan hasil penelitian ini juga tidak mendukung penelitian dari Brown \& Tucker (2011). Pasar dalam penelitian ini diproksikan dengan Abnormal Return akan bereaksi dengan pengungkapan MD\&A ditunjukkan dengan pengaruh MD\&A terhadap abnormal return sebesar 5,4\%. Tingginya tingkat pengungkapan MD\&A berpengaruh pada pasar karena dapat meminimalkan asimetri informasi antara prisipal dan agen. 
Penelitian ini diharapkan dapat memberikan kontribusi positif bagi semua pihak khususnya investor, perusahaan, dan regulator. Bagi pihak perusahaan baiknya untuk mengungkapkan informasi yang lebih terbuka guna mengurangi asimetri informasi. Pengungkapan informasi dalam MD\&A yang terbuka dan lengkap sesuai dengan ketentuan bisa menjadi salah satu nilai tambah tersendiri bagi perusahaan yang mengungkapkan.

Bagi para investor hendaknya tidak hanya terpaku pada informasi keuangan yang berupa data kuantitatif dari laporan keuangan saja dalam menentukan keputusan investasi, ada baiknya jika memasukkan data kualitatif mengenai perusahaan yang terdapat dalam MD\&A karena informasi yang diungkapkan MD\&A yang baik terdapat informasi lampau, terkini, dan prospek perusahaan mendatang. Investor di Indonesia sendiri sudah menggunakan informasi MD\&A dalam menentukan keputusan investasi yang dibuktikan dalam penelitian ini bahwa pengungkapan MD\&A memberikan pengaruh pada reaksi pasar.

Bagi regulator khususnya OJK agar memperluas lagi kriteria MD\&A yang wajib untuk diungkapkan guna mendorong pengungkapan yang lebih terbuka oleh perusahaan atau emiten. Selain itu juga agar dapat memperketat pengawasan terutama pada hal apa saja yang wajib diungkapkan dalam laporan keuangan tahunan serta memberikan sanksi bagi perusahaan yang tidak mengungkapkan informasi dalam MD\&A yang sifatnya mandatory. Hasil dalam penelitian ini menunujukkan bahwa beberapa emiten tidak melengkapi atau mengungkapkan 
informasi yang menjadi kewajiban perusahaan untuk mengungkapkan informasi tersebut di MD\&A.

\section{SIMPULAN}

Tujuan dari penelitian ini adalah untuk mencari pengaruh pengungkapan MD\&A terhadap reaksi pasar yang diproksikan dengan abnormal return dan TVA. Berdasarkan hasil analisis dan pembahasan pada bab sebelumnya, maka dapat disimpulkan bahwa (1)Terdapat reaksi oleh pasar pada saat pengumuman laporan tahunan emiten, (2)Pengungkapan MD\&A berpengaruh positif dan signifikan terhadap average abnormal return, (3)Pengungkapan MD\&A berpengaruh positif dan signifikan terhadap Trading Volume Activity.

Saran yang diberikan kepada investor, perusahaan, dan regulator yakni : (1)Investor sebaiknya memperhatikan informasi kualitatif dari laporan keuangan tahunan emiten dan tidak hanya menggunakan informasi kuantitatif saja dalam menentukan keputusan investasi karena didalam MD\&A terdapat informasi yang cukup lengkap tentang masa lampau, terkini dan prospek bisnis perusahaan kedepan. (2)Perusahaan khususnya emiten dalam hal ini sebaiknya mengungkapkan informasi MD\&A minimal untuk poin yang diwajibkan oleh regulator guna meminimalkan asimetri informasi dan juga untuk membantu investor maupun kreditur dalam mengestimasi nilai perusahaan, (2)Regulator/ OJK Regulator pasar modal di Indonesia dapat mengawasi kualitas dari MD\&A terutama konten dari MD\&A yang bersifat mandatory karena ada beberapa perusahaan yang menjadi sampel dalam penelitian ini tidak mengungkapkan 
konten wajib dalam MD\&A. (3)Peneliti kedepannya agar menggunakan sampel yang lebih banyak dan menggunakan data time series. Selain itu juga kedepannya agar menggunakan kriteria yang terbaru dari Annual Report Award.

\section{REFERENSI}

Apriyanti and Sidanti, H. (2018) 'Perbedaan Abnormal Return Dan Volume Perdagangan Saham Sebelum Dan Setelah Pengumuman Pemenang Award Tahun 2014 Pada Perusahaan Yang Listing Di Bursa Efek Indonesia', Ekuilibrium : Jurnal Ilmiah Bidang Ilmu Ekonomi, 11(2), p. 91. doi: 10.24269/ekuilibrium.v11i2.209.

Audi, R., Loughran, T. and Mcdonald, B. (2015) 'Trust, but Verify: MD \& A Language and the Role of Trust in Corporate Culture', Journal of Business Ethics. Springer Netherlands. doi: 10.1007/s10551-015-2659-4.

Brown, S. V. and Tucker, J. W. (2011) 'Large-Sample Evidence on Firms' Yearover-Year MD\&A Modifications', Journal of Accounting Research, 49(2), pp. 309-346. doi: 10.1111/j.1475-679X.2010.00396.x.

Bryan, S. H. and Bryan, S. H. (2014) 'of in Required Information Disclosures Content Contained Management Discussion and Analysis', 72(2), pp. 285301.

Ekawati, R. K. (2011) 'Analisis Perbedaan Harga Saham Sebelum Dan Sesudah Pengumuman Annual Report Awards ( ARA ) Di Bursa Efek Jakarta', Jurnal Ilmiah STIE MDP, 1(1), pp. 33-41.

Epstein, M. J. and Pava, M. L. (1995) 'Shareholders' Perceptions on The Usefulness Of MD \& AS', Emerald Insight, 21(3), pp. 68-83. doi: http://dx.doi.org/10.1108/eb018507.

Francis, J. and Schipper, K. (2013) 'Have Financial Statements Lost Their Relevance?', Journal of Accounting Research, 37(2), pp. 319-352. Available at: http://www.jstor.org/stable/2491412 .

Gunawan, H. and Lina, E. O. (2015) 'Mandatory and voluntary disclosure of annual report on investor reaction', in International Journal of Economics and Financial Issues, pp. 311-314. Available at: https://www.scopus.com/inward/record.uri?eid=2-s2.084937830957\&partnerID=40\&md5=639715c4056b887f41167b6fa6ab711 2. 
Hartono, J. (2017) Teori Portofolio dan Analisis Investasi. Edisi Kese. Yogyakarta: BPFE Yogyakarta.

Haw, I.-M., Qi, D. and Wu, W. (2000) 'Timeliness of Annual Report Releases and Market Reaction to Earnings Announcements in an Emerging Capital Market: The Case of China In-Mu', Journal of International Financial Management and Accounting, 11(2), pp. 108-129.

Koonce, L., Seybert, N. and Smith, J. (2016) 'Management Speaks, Investors Listen: Are Investors Too Focused on Managerial Disclosures?', Journal of Behavioral Finance, 17(1), pp. 31-44. doi: 10.1080/15427560.2016.1133623.

Kristi, Y., Rodney, R. and Jesse F, D. (2002) 'Communicative action and corporate annual reports', Journal of Business Ethics, 41(1-2), pp. 141157. doi: 10.1023/A:1021314626311.

Li, H. (2017) 'Repetitive Disclosures in the MD\&A', Ssrn. doi: $10.2139 /$ ssrn.2924193.

Lindrianasari, Gultom, S. B. and Alvia, L. (2017) 'Management discussion and analysis, corporate governance perception index and market reaction', Corporate Ownership and Control, 14(4), pp. 165-175. doi: 10.22495/cocv14i4art14.

Lo, K., Ramos, F. and Rogo, R. (2017) 'Earnings management and annual report readability', Journal of Accounting and Economics. Elsevier, 63(1), pp. 125. doi: 10.1016/j.jacceco.2016.09.002.

Mayew, W. J. (2012) 'Disclosure Outlets and Corporate Financial Communication: A Discussion of "Managers" Use of Language Across Alternative Disclosure Outlets: Earnings Press Releases versus MD\&A"'”, Contemporary Accounting Research, 29(3), pp. 838-844. doi: 10.1111/j.1911-3846.2011.01126.x.

Mayew, W. J., Sethuraman, M. and Venkatachalam, M. (2015) 'MD \& A Disclosure and The Firm's Ability to Continue as a Going Concern', The Accounting Review, 90(4), pp. 1621-1651. doi: http://dx.doi.org/10.2308/accr-50983.

Paramita, R. W. D. and Rizal, N. (2015) 'Internet Financial Report: Respons Pasar Sebelum dan Sesudah Tanggal Publikasi', 8(2), pp. 68-74. Available at: http://dev2.kopertis7.go.id/uploadjurnal/Ekonomika Vol 8 No 2 Des 2015_siap cetak.pdf\#page $=30$.

Pevzner, M., Xie, F. and Xin, X. (2015) 'When firms talk, do investors listen? The 
role of trust in stock market reactions to corporate earnings announcements', Journal of Financial Economics. Elsevier, 117(1), pp. 190-223. doi: 10.1016/j.jfineco.2013.08.004.

Rizki, A. (2015) 'Pengaruh Luas Pengungkapan Sukarela dalam Laporan Tahunan Terhadap Return dan Harga Saham', Symposium Nasional Akuntansi. Available at: http://lib.ibs.ac.id/materi/Prosiding/SNA XVIII/makalah/044.pdf.

Sriwidodo, U. and Sumaryanto (2017) 'Perbedaan Harga Saham, Abnormal Return, dan Volume Perdagangan Saham Sebelum dan Sesudah Pengumuman Annual Report', in Riset Fair. Riset Fair 2017.

Sugiyono (2017) Metode Penelitian Kuantitatif dan Kualitatif. Bandung: Alfabeta.

Sun, Y. (2010) 'Do MD\&A disclosures help users interpret disproportionate inventory increases?', Accounting Review, 85(4), pp. 1411-1440. doi: 10.2308/accr.2010.85.4.1411.

Tennyson, B. M., Ingram, R. W. and Dugan, M. T. (1990) 'Assessing the information content of narrative disclosure in explaining bankruptcy', Journal of Business Finance \& Accounting, 17(3), pp. 391-410. doi: 10.1111/j.1468-5957.1990.tb01193.x.

Widiastuti, H. (2004) 'Pengaruh Luas Ungkapan Sukarela dalam Laporan Tahunan terhadap Earnings Response Coefficient ( ERC )', 5(2), pp. 187207. Available at: http://journal.umy.ac.id/index.php/ai/article/view/983. 